(c) Elsevier Sequoia S.A., Lausanne - Printed in The Netherlands

\title{
A HIGH-PRECISION NETWORK ANALYZER SYSTEM FOR THE MEASUREMENT OF THE ELECTRODE IMPEDANCE OF BOTH STATIONARY AND NON-STATIONARY ELECTRODE, WITH SPECIAL ATTENTION TO THE DROPPING MERCURY ELECTRODE
}

\author{
C.P.M. BONGENAAR, M. SLUYTERS-REHBACH and J.H. SLUYTERS \\ Van't Hoff Laboratory, State University of Utrecht, Padualaan 8, 3584 CH Utrecht (The \\ Netherlands)
}

(Received 1st September 1979; in revised form 29th October 1979)

\section{ABSTRACT}

A largely automatic instrument for the measurement of the admittance of a galvanic cell is described. During a measurement the frequency of the alternating voltage and the dc voltage are scanned stepwise in a programmed sequence. A high precision has been obtained by applying a programmed correction procedure and an automatic correction for short-term drift.

The performance of the instrument is demonstrated on a dummy cell, a cell with supporting electrolyte only and on the determination of the kinetic parameters of the fast $\mathrm{Cd}$ (II) ion reduction on the DME in $1 \mathrm{M} \mathrm{KCl}$.

\section{(I) INTRODUCTION}

In the past the impedance method has proved to be a powerful method for the study of electrochemical cells. The method may be applied for several purposes, e.g. characterization of an electrochemical object to find possible mechanisms in electrochemical processes, or in electroanalytical chemistry. In the last two cases the electrochemical object is mostly the dropping mercury (DME), because of its advantages of reproducibility and relative chemical inertness.

When accurate measurements were required, ac bridges [1-4] were long considered to be superior to direct-measuring, phase-sensitive devices [5-11]. However, the (manual) operation of an ac bridge is tedious and time-consuming, especially in the case of a non-stationary object. In particular, in studies of electrode processes, it is increasingly recognized that many data points are needed, in both a wide frequency and a wide dc potential range, in order to be able to distinguish the possible contributions of charge transfer, diffusional mass transport, coupled chemical reactions and adsorption phenomena. It is therefore understandable that in recent developments much effort has been devoted to design more or less automatically operated, directmeasuring devices. For example, Huebert [12], using several tuned amplifiers, was able to apply a number of frequencies simultaneously to the cell, but still 
at the expense of accuracy compared to bridge measurements.

Later, an improvement in this respect was effected by Creason and Smith [13--15], using a minicomputer to control the measurements and to acquire data with the aid of the Fast Fourier transform algorithm. The disadvantage of this set-up was the very limited bandwidth $(1 \mathrm{kHz})$ caused by a phase-shifting potentiostat and a relatively low sampling speed. Recently Schwall and Smith [16-18] extended the system in such a way that these problems were overcome, which resulted into a very powerful automatic measuring device covering a frequency range of $10 \mathrm{~Hz}$ up to $125 \mathrm{kHz}$. The essential feature is that the whole frequency spectrum is obtained in one measurement, but that several measurements have to be averaged in order to acquire the desired accuracy.

The alternative to the Fast Fourier approach is still the direct-measuring, phase-sensitive detector, now with better electronics than formerly, e.g. a Solartron frequency response analyzer, in use by Armstrong et al. [19] or a Hewlett-Packard automatic network analyzer system, which was installed in our laboratory with the special purpose to perform highly accurate impedance measurements at (among others) the DME. With this system all the desired points in the frequency spectrum are measured sequentially, averaging being unnecessary. It is the aim of this paper to describe the features of this system and to demonstrate some experimental results obtained with the $\mathrm{Cd}(\mathrm{II}) / \mathrm{Cd}(\mathrm{Hg})$ electrode reaction in a $1 M \mathrm{KCl}$ supporting electrolyte solution.

\section{(II) EXPERIMENTAL}

\section{(II.1) Parts of the set-up and their arrangement}

The complete set-up is represented schematically in Fig. 1. The ac and the two dc input signals to the potentiostat are generated by the frequency synthesizer FS and the two digital to analog converters DAC. The sum of these input signals is applied to the cell via the potentiostat $\mathrm{P}$, built in this laboratory following the design of Brown et al. [20]. The connections between cell and potentiostat are made via switches in such a way that it is possible to replace the cell by a dummy resistor $R$. These switches can be operated automatically with the aid of a relay actuator RA.

The ac current output and the control amplifier output of the potentiostat are connected to the input channels $\mathrm{A}$ and $\mathrm{B}$ of the network analyzer NA respectively. The network analyzer measures the differences between the logarithm of the amplitudes of these two signals and the phase angle between them. The internal time delay between amplitude and phase measurements is negligibly small $(2 \mathrm{~ms})$. Either the dc current output or the dc potential of the indicator electrode can be measured by the digital voltmeter DVM at will via a manually operated switch.

The way in which the potentiostat and the network analyzer are connected, needs some further explanation. Taking, as is usually done, the voltage of the reference electrode or of the electrometer amplifier output as the voltage output would have the advantage of eliminating the impedance of the counter electrode completely and, in addition, a considerable part of the ohmic drop in the electrolyte solution. However, our experiments showed that in that con- 


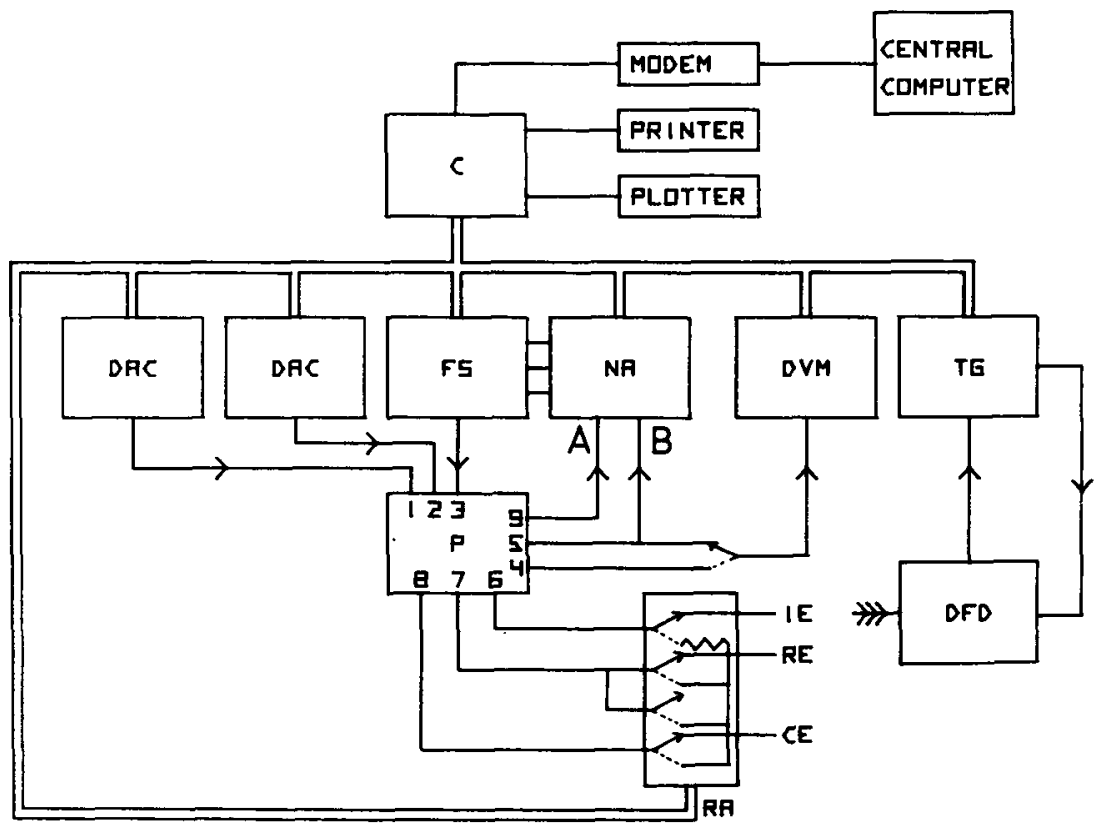

Fig. 1. Network analyzer configuration. C: calculator HP 9830A; DAC: digital analog converter HP 59303A; FS: frequency synthesizer HP 3320B; NA: network analyzer HP 3570A; DVM: digital multimeter HP 3455; TG: timing generator HP 59308A; P: potentiostat; DFD: drop fall detector; RA: relay actuator HP 58306A; MODEM: sematrans 202; PRINTER: HP 9866A; PLOTTER: HP 9862A; CE: counter electrode; RE: reference electrode; IE: indicator electrode; A and B: channel A and B network analyzer inputs.

figuration serious phase errors are introduced. Therefore, we preferred to measure the voltage at the counter electrode instead. It will be clear that in this way always the total cell impedance is measured, including solution resistance and counter-electrode impedance. The latter can, of course, be made negligible in many cases. The advantage of our configuration is that the values of the condensers $\mathrm{C}_{1}$ and $\mathrm{C}_{2}$ and the bandwidths of the amplifiers $\mathrm{OA}_{1}$ and $\mathrm{OA}_{2}$ are unimportant. The details of the circuitry in and around the potentiostat are shown in Fig. 2.

Returning to Fig. 1, it can be seen that the equipment includes a drop fall detector DFD, as described earlier [21] and a timing generator TG, to be able to measure at preset times.

All instruments are under direct control of the desk calculator $\mathrm{C}$ via the HP-interface bus system. The calculator is programmed in BASIC and is equipped with a line printer ( 72 characters) and a plotter. Furthermore, the calculator can be used as an interactive terminal to a large central computer (CYBER 73/26).

\section{(II,2) The specifications}

The potentialities of our set-up may be indicated by the following specifications. 


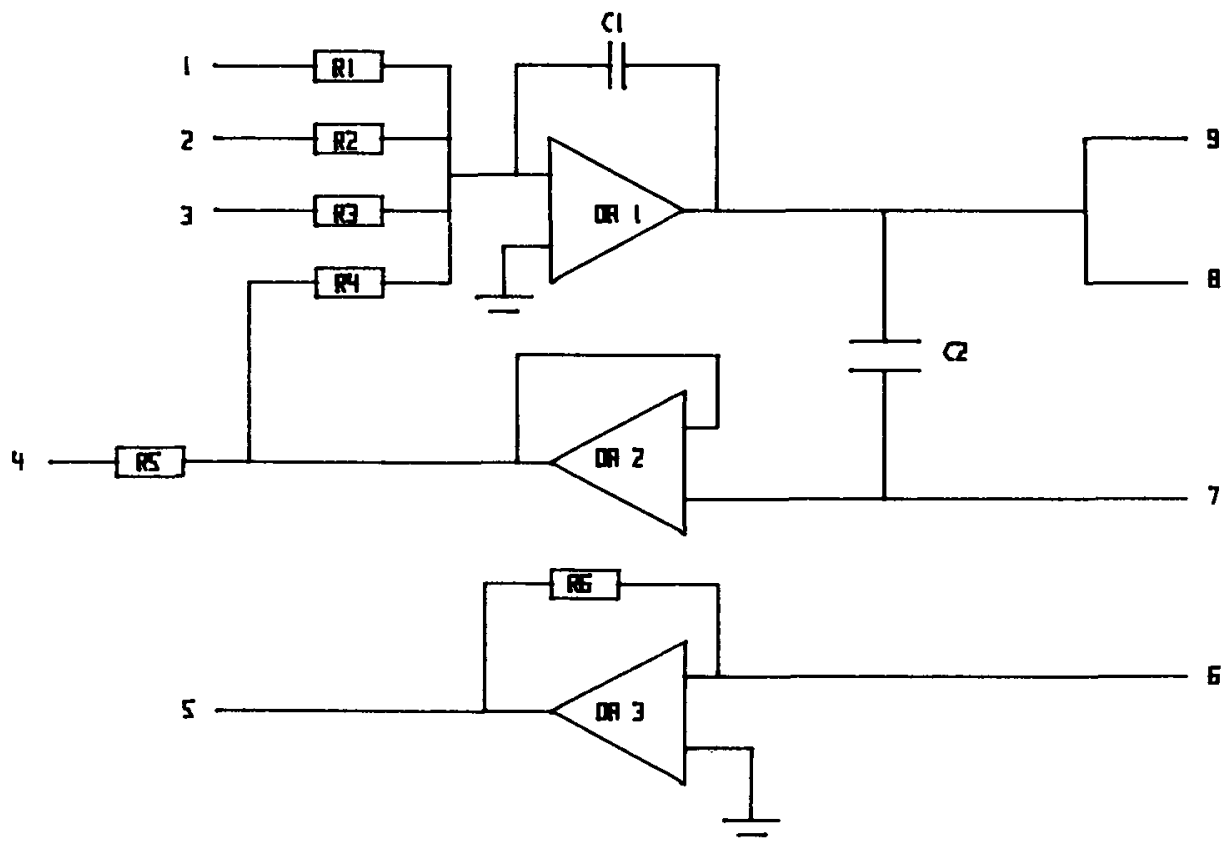

Fig. 2. Potentiostat. OA1: operational amplifier SN 72741; OA2: operational amplifier AD 148B; OA3: operational amplifier BB 3550J; $R_{1}$ and $R_{4}: 10 \mathrm{k} \Omega 1 \%$; $R_{2}: 100 \mathrm{k} \Omega 1 \%$; $R_{3}$ : $220 \mathrm{k} \Omega 1 \% ; \mathrm{R}_{5}: 100 \Omega 1 \% ; \mathrm{R}_{6}: 1 \mathrm{k} \Omega 1 \%$; $\mathrm{C} 1: 120 \mathrm{pF} ; \mathrm{C} 2: 3 \mathrm{nF} ; 1-9$ : corresponding connections of Fig. 1.

(1) Frequency range: $70 \mathrm{~Hz}$ to $50 \mathrm{kHz}$. Higher frequencies up to $20 \mathrm{MHz}$ are possible, but great care should than be taken to avoid shield capacitances due to the cables between cell, potentiostat and relay actuator.

(2) AC potential amplitude: variable between $+19 \mathrm{dBm}$ and $-72 \mathrm{dBm}$.

(3) DC potential: both DA converters cover a range of -10 to $+10 \mathrm{~V}$; one $\mathrm{DAC}$ is used in that way, the ouput of the other is added via a $1: 10$ divider, so that the total range is --11 to $+11 \mathrm{~V}$ with a resolution of $1 \mathrm{mV}$. The dc potential measured at the reference electrode by the DVM appears to be constant within $30 \mu \mathrm{V}$, if the cell is working properly. DC current measurements are made by sampling at the desired time.

(4) AC measurements: the dynamic range of the network analyzer is $120 \mathrm{~dB}$, its resolution $0.01 \mathrm{~dB}$. Owing to imperfect logarithmic amplifiers there is a maximal error of $0.3 \mathrm{~dB}$ in the amplitude ratio and ca. $1^{\circ}$ in the phase angle. These errors are systematic and appear to be functions of the amplitude and the frequency. In view of the desired accuracy the magnitudes of these errors are unacceptable, but thanks to their constancy in time it appeared possible to develop an automatic correction procedure in the following way.

The cell is replaced by a non-reactive resistance variable between $35 \Omega$ and $10 \mathrm{k} \Omega$. Because the resistor across the current follower amplifier is $1000 \Omega$ this means that the logarithm of the amplitude ratio (channel A minus channel B) varies from $-20 \mathrm{~dB}$ to $+32 \mathrm{~dB}$. The amplitude ratios and phase shifts are measured in this range and compared to the theoretical values (calculated dB-value 
and $0^{\circ}$ phase angle), thus resulting in amplitude errors $\Delta \mathrm{dB}$ and phase angle errors $\Delta \phi$ as a function of amplitude ratio. This calibration is performed at a number (20) of selected frequencies between $70 \mathrm{~Hz}$ and $50 \mathrm{kHz}$. At each frequency the $\Delta \phi$-values vs. dB-values are fitted to a sixth-degree polynomial and the coefficients are stored. The $\Delta \mathrm{dB}$-values are stored unprocessed in array form. Since the amplitude errors were found to be independent of frequency, only the array pertaining to $1 \mathrm{kHz}$ was maintained in practice. With these calibration data each measured impedance can easily be corrected digitally either immediately or later. To give an idea of the errors involved, $\Delta \phi$ and $\Delta$ dB-values at $1 \mathrm{kHz}$ are reproduced in Figs. 3 and 4 .

Another source of error can be the short-term temperature drift of the instrument. To eliminate this a $1000 \Omega$ precision resistor (Vishay) is connected to the switches of the relay actuator (see Fig. 1) so that after each cell measurement a calibration can be performed. A deviation from $0 \mathrm{~dB}$ and $0^{\circ}$ phase angle is then immediately corrected in the obtained amplitude and phase angle for the unknown. In order to prevent the potentiostat from oscillating, the switching sequence is programmed in such a way that "make before break" is always effected.

From tests with dummy cell configurations (a resistor and a capacitor in series) it has been found that with these correction procedures errors are reduced to $0.5 \%$ in the absolute value of the dummy impedance and $0.15^{\circ}$ in its phase angle.

A final item to discuss is the response time of the network analyzer. The instrument converts the input signal to a signal of $100 \mathrm{kHz}$ which is then bandpass filtered. For a sufficient noise rejection we mostly use the smallest bandwidth facility of $10 \mathrm{~Hz}$. However, this involves a rather large time constant, 87 $\mathrm{ms}$, and thus a slow settling after an abrupt signal change, or a lagging response to a time-dependent signal. Recently, we discussed the consequences of this

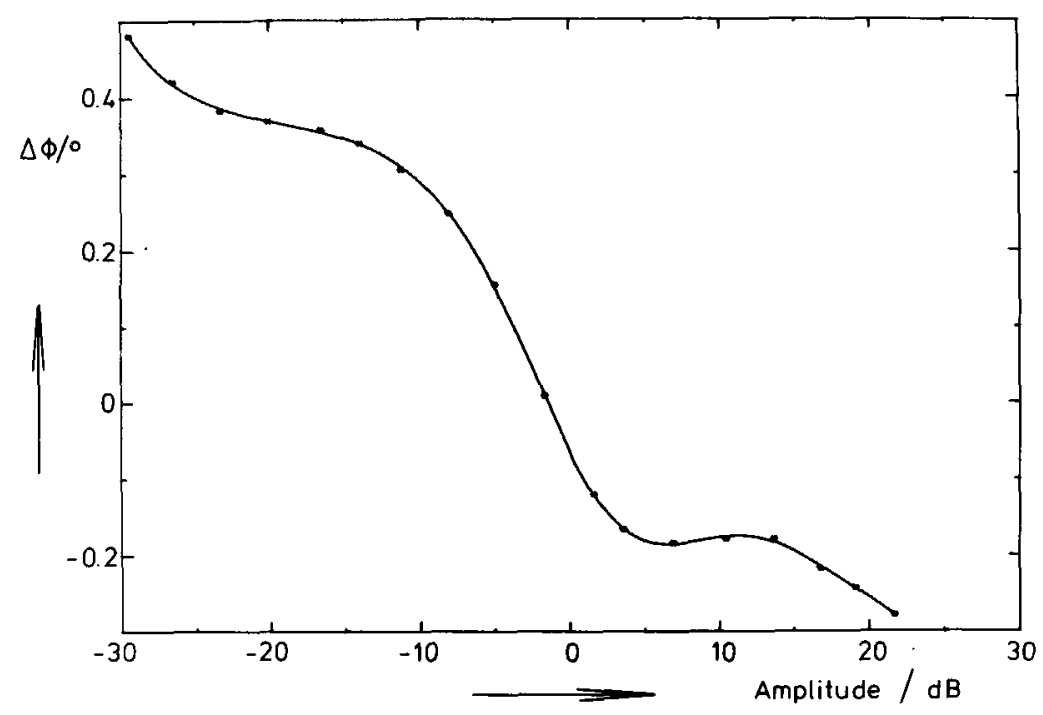

Fig. 3. Phase calibration as function of amplitude at $1000 \mathrm{~Hz}$. 


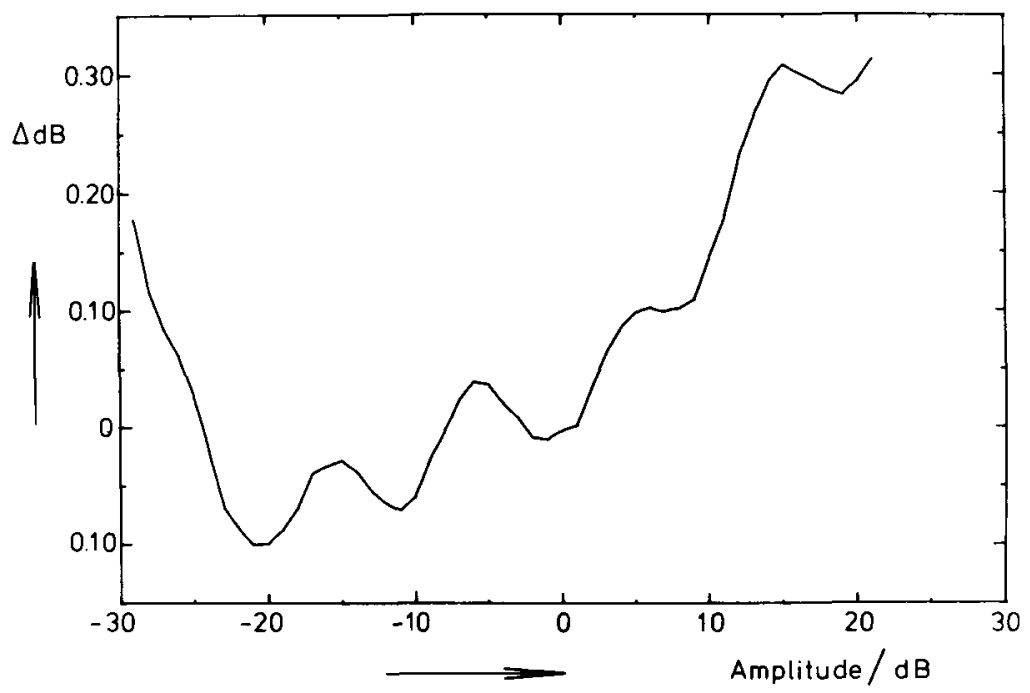

Fig. 4. Amplitude calibration as function of the amplitude at $1000 \mathrm{~Hz}$.

effect in the case of a DME [22]. At normal drop times errors of about $1 \%$ can be expected. We will return to this problem in Section (III).

\section{(II.3) Processing and data acquisition}

With the HP system, control of the actions to be performed by the various instruments is very easy, the commands to be given requiring usually only one or two line statements. The course of an experiment can therefore be programmed in various ways. As an example we give in Fig. 5 a flow chart of our program for measurements with scanned potential and frequency at the DME.

As previously mentioned, each sample is followed by switching to the $1000 \Omega$ resistor for immediate calibration. This has the result that it takes three drops to measure one data point. A normal series of measurements -20 potentials, 20 frequencies - is then completed within $2 \mathrm{~h} 30 \mathrm{~min}$ (an experienced operator would need several days to collect the same series with an ac bridge). It is therefore possible to measure the impedance of the DME in the supporting electrolyte first and then to add the electroactive substance to the same cell for the actual measurements.

A complication is introduced by the drop-fall detector used. The internal $100 \mathrm{MHz}$ oscillator seriously influences the dc potential of the DME: potential shifts of $50 \mathrm{mV}$ can easily occur. Therefore, immediately after drop fall the DFD triggers the clock and then switches off the $100 \mathrm{MHz}$ oscillator. After a preset (programmable) time delay the clock triggers the network analyzer and starts the oscillator in the DFD after the sample has been taken. In this way the electrode is kept at the desired potential from drop birth to beyond the moment of sampling.

The data are collected in memory and eventually stored on magnetic tape. Mostly simple analyses (complex plane plots, calculations of interfacial admittance) are performed on the calculator itself. For final fitting procedures the data can be transmitted to the CYBER 37/26. More details inherent to the 


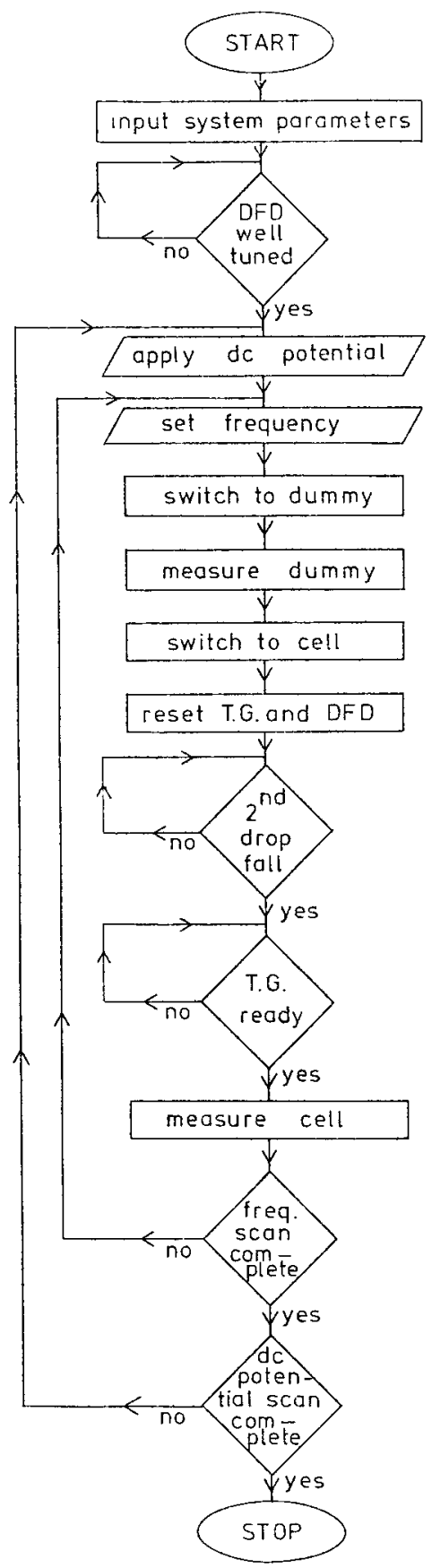

Fig. 5. Flow chart of measuring program.

problem of fitting will be discussed in a separate paper [23]. Mostly preliminary analyses (complex plane plots, calculations of interfacial admittance) are performed on the calculator itself. For final fitting procedures the data can be transmitted to the CYBER 73/26. More details inherent to the problems of fitting will be discussed in a separate paper [23]. 


\section{(II.4) Cell and electrodes}

An ordinary polarographic cell with a capacity of $50 \mathrm{ml}$ was used. The capillary for the DME was drawn out to an outer diameter of about $0.3 \mathrm{~mm}$ to avoid shielding as much as possible. The natural drop time was ca. 6 s. Measurements were taken at $4 \mathrm{~s}$ after drop birth. The area at that time was $3.34 \mathrm{~mm}^{2}$. The counter electrode was a mercury pool with an area of $15 \mathrm{~cm}^{2}$. A saturated calomel electrode (SCE), connected to the cell via a salt bridge filled with cell solution, served as the reference electrode. The temperature of the cell was kept at $25^{\circ} \pm 0.1^{\circ}$. Deaeration was established by argon freed from traces of oxygen by means of a BTS copper catalyst.

The system studied was a solution of $1 \mathrm{M} \mathrm{KCl}$ in triply distilled water with $\mathrm{CdSO}_{4} 8 / 3$ aq. added to a concentration of $0.56 \mathrm{~m} M$.

\section{(III) RESULTS AND DISCUSSION}

\section{(III.1) Dummy cell}

A typical dummy cell experiment is shown in Table 1. It can be seen that up to $20 \mathrm{kHz}$ the amplitude and phase errors are within the specifications previously mentioned. However, when the amplitude and phase data are trans-

\section{TABLE 1}

Comparison of theoretical and measured impedances of a RC network consisting of a $100 \Omega$ resistor and a $1 \mu \mathrm{F}$ capacitor in series

\begin{tabular}{|c|c|c|c|c|c|c|}
\hline \multirow{2}{*}{$\begin{array}{l}\text { Freq./ } \\
\mathrm{Hz}\end{array}$} & \multicolumn{2}{|l|}{ Theoretical } & \multicolumn{2}{|l|}{ Measured } & \multicolumn{2}{|c|}{ Measured } \\
\hline & $\begin{array}{l}\text { amplitude/ } \\
\Omega\end{array}$ & phase/ & $\begin{array}{l}\text { amplitude/ } \\
\Omega\end{array}$ & phase/ & $\begin{array}{l}R_{\mathrm{s}} l \\
\Omega\end{array}$ & $\begin{array}{l}C_{\mathrm{s}} / \\
\mu \mathrm{F}\end{array}$ \\
\hline 70 & 2275.8 & 87.48 & 2275.9 & 87.44 & 101.8 & 0.999 \\
\hline 120 & 1330.1 & 85.69 & 1330.1 & 85.65 & 100.8 & 1.000 \\
\hline 170 & 941.5 & 83.90 & 941.6 & 83.86 & 100.4 & 1.002 \\
\hline 220 & 730.3 & 82.13 & 730.3 & 82.11 & 100.0 & 1.003 \\
\hline 320 & 507.3 & 78.63 & 507.4 & 78.57 & 100.2 & 1.003 \\
\hline 420 & 391.9 & 75.22 & 392.0 & 75.12 & 100.3 & 1.004 \\
\hline 520 & 322.0 & 71.91 & 319.1 & 71.82 & 100.1 & 1.004 \\
\hline 720 & 242.6 & 65.66 & 240.6 & 65.55 & 100.0 & 1.005 \\
\hline 1.000 & 188.0 & 57.86 & 188.0 & 57.73 & 100.0 & 1.005 \\
\hline 1.500 & 145.8 & 46.70 & 144.9 & 46.53 & 99.8 & 1.008 \\
\hline 2.000 & 127.8 & 38.51 & 127.2 & 38.32 & 99.9 & 1.008 \\
\hline 3.000 & 113.2 & 27.95 & 112.7 & 27.78 & 99.7 & 1.010 \\
\hline 4.000 & 107.6 & 21.70 & 107.2 & 21.52 & 99.7 & 1.012 \\
\hline 5.000 & 104.9 & 17.66 & 104.7 & 17.49 & 99.8 & 1.012 \\
\hline 7.000 & 102.6 & 12.81 & 102.4 & 12.65 & 99.9 & 1.014 \\
\hline 10.000 & 101.3 & 9.04 & 100.9 & 8.95 & 99.7 & 1.014 \\
\hline 15.000 & 100.6 & 6.06 & 100.3 & 5.90 & 99.8 & 1.028 \\
\hline 20.000 & 100.3 & 4.55 & 100.1 & 4.41 & 99.8 & 1.034 \\
\hline 30.000 & 100.1 & 3.04 & 99.9 & 2.81 & 99.8 & 1.084 \\
\hline 50.000 & 100.1 & 1.82 & 100.0 & 1.48 & 100.0 & 1.233 \\
\hline
\end{tabular}


TABLE 2

Results obtained at the DME in a solution of $1 M \mathrm{KCl}$ at $-0.628 \mathrm{~V}$ vs. SCE

\begin{tabular}{rrrr}
\hline Freq./Hz & $R_{\mathrm{s}} / \Omega$ & $C_{\mathrm{s}} / \mu \mathrm{F}$ & $C_{\mathrm{s}} / \mu \mathrm{F}^{\mathrm{a}}$ \\
\hline 70 & 106.8 & 1.403 & 1.404 \\
120 & 77.5 & 1.392 & 1.392 \\
170 & 68.6 & 1.391 & 1.387 \\
220 & 63.9 & 1.386 & 1.382 \\
320 & 60.8 & 1.393 & 1.379 \\
420 & 59.7 & 1.381 & 1.375 \\
520 & 59.0 & 1.385 & 1.379 \\
720 & 58.3 & 1.381 & 1.374 \\
1.000 & 57.7 & 1.382 & 1.376 \\
1.500 & 57.4 & 1.385 & 1.374 \\
2.000 & 57.1 & 1.390 & 1.379 \\
3.000 & 56.9 & 1.392 & 1.378 \\
4.000 & 56.9 & 1.393 & 1.376 \\
5.000 & 56.9 & 1.394 & 1.377 \\
7.000 & 56.7 & 1.404 & 1.385 \\
10.000 & 56.7 & 1.412 & 1.393 \\
15.000 & 56.7 & 1.441 & 1.403 \\
20.000 & 56.6 & 1.478 & 1.424 \\
30.000 & 56.5 & 1.595 & 1.471 \\
50.000 & 56.4 & 2.177 & 1.766 \\
\hline
\end{tabular}

${ }^{\text {a }} C_{\mathrm{s}}$ corrected according to eqn. (1).

formed into the measured $R_{\mathrm{s}}$ and $C_{\mathrm{s}}$, the apparent $C_{\mathrm{s}}$-value systematically deviates more and more from the theoretical one with increasing frequency.

\section{(III.2) Supporting electrolyte}

The measurements in the supporting electrolyte may serve to obtain an indication of the reliability of the raw data obtained with a cell. Therefore the primary data, amplitude and phase angle, are converted to give the components $Z^{\prime}$ (in-phase) and $Z^{\prime \prime}$ (quadrature) of the cell impedance and finally the elements of the supposed equivalent circuit, i.e. the series resistance $R_{\mathrm{s}}=Z^{\prime}$ and the series capacitance $C_{\mathrm{s}}=\left(\omega Z^{\prime \prime}\right)^{-1}$. Typical results are given in Table 2 .

In the frequency range $70 \mathrm{~Hz}$ to $7 \mathrm{kHz}$ the $C_{\mathrm{s}}$-values do not differ more than $1 \%$, which is in accordance with the specific amplitude and phase errors. At higher frequencies systematic deviations are always found beyond these errors. These deviations are similar to those found with the dummy. Therefore, we decided to correct the $C_{\mathrm{s}}$-values at frequencies from $220 \mathrm{~Hz}$ up to $10 \mathrm{kHz}$ following the relation:

$\left[\frac{C_{\mathrm{s}} \text { (true) }}{\left.C_{\mathrm{s}} \text { (measured) }\right)}\right]_{\text {cell }}=\left[\frac{C_{\mathrm{s}} \text { (true) }}{\left.C_{\mathrm{s}} \text { (measured }\right)}\right]_{\mathrm{dummy}}$

The corrected $C_{\mathrm{s}}$-values are shown in the third column of Table 2 . The $R_{\mathrm{s}}$-data for the supporting electrolyte are severely frequency dependent in a way corresponding to the so-called capillary response effect. 


\section{(III.3) The cadmium reduction}

The measurements made after addition of the $\mathrm{Cd}(\mathrm{II})$ salt have also been acquired in terms of $R_{\mathrm{s}}$ and $C_{\mathrm{s}}$, or at choice as $Z^{\prime}$ and $Z^{\prime \prime}$. Following evidence in the literature [3,24-27] data were analyzed assuming Randles behaviour. Since the reaction is reported to be very fast, this is most easily done in terms of the parameters $\sigma$ (Warburg coefficient) and $p^{\prime}$ (quotient of charge-transfer resistance and Warburg coefficient) using the equations [28]:

$$
\begin{aligned}
& Y=Y^{\prime}+\mathrm{j} Y^{\prime \prime}=\frac{\left(Z^{\prime}-R_{\Omega}\right)+\mathrm{j}\left(Z^{\prime \prime}\right)}{\left(Z^{\prime}-R_{\Omega}\right)^{2}+\left(Z^{\prime \prime}\right)^{2}} \\
& Y^{\prime}=\frac{\omega^{1 / 2}}{\sigma} \frac{p+1}{p^{2}+2 p+2} \\
& Y^{\prime \prime}=\frac{\omega^{1 / 2}}{\sigma} \frac{1}{p^{2}+2 p+2}+\omega C_{\mathrm{d}} \\
& p=p^{\prime} \omega^{1 / 2}
\end{aligned}
$$

If Randles behaviour prevails, the data must fit to these equations, while moreover, $p^{\prime}$ and $\sigma$ should obey the expressions [29]:

$$
\begin{aligned}
& p^{\prime}=\left[\left(2 D_{\mathrm{O}}\right)^{1 / 2} / k_{\mathrm{f}}\right][1+\exp (\mathrm{j})]^{-1} \\
& \sigma=\frac{R T \exp (\mathrm{j})+2+\exp (-\mathrm{j})}{n^{2} F^{2}} F_{\mathrm{O}}\left(2 D_{\mathrm{O}}\right)^{1 / 2} \\
& \mathrm{j}=(n F / R T)\left(E-E_{1 / 2}^{\mathrm{r}}\right)
\end{aligned}
$$

where $E_{1 / 2}^{\mathrm{r}}$ is the reversible half-wave potential, $D_{\mathrm{O}}$ the diffusion coefficient and $c_{\mathrm{O}}$ the bulk concentration of the oxidized species, and $k_{\mathrm{f}}$ the forward rate constant. In $F(t)$ both the influence of $k_{\mathrm{f}}$ and the geometry of the electrode on the dc behaviour are incorporated.

After substitution of $R_{\Omega}$ obtained outside the faradaic region $(0.4 \mathrm{~V}$ positive or negative to $E_{1 / 2}$ ) at $10 \mathrm{kHz}, Y^{\prime}$ and $Y^{\prime \prime}$ are calculated using eqn. (2).

In Fig. $6, \omega^{1 / 2} / Y^{\prime}$ is plotted against $\omega^{1 / 2}$ for three different potentials. From the constancy of this function in (nearly) the whole frequency range it follows that the term in $p,\left(p^{2}+2 p+2\right) /(p+1)$ is virtually independent of frequency within experimental error. It can be calculated that this must mean that $p^{\prime} \leqslant$ $10^{-3} \mathrm{~s}^{1 / 2}$ and that $\omega^{1 / 2} / Y^{\prime}$ equals $2 \sigma$. So, only $\sigma$ can be determined from the in-phase interfacial admittance component. The resulting values are plotted vs. dc potential in Fig. 7 .

The curve drawn in Fig. 7 has been calculated with the aid of eqn. (6), taking the diffusion layer model for $F(t), D_{\mathrm{O}}=9 \times 10^{-6} \mathrm{~cm}^{2} \mathrm{~s}^{-1}, D_{\mathrm{R}}=1.07 \times 10^{-5}$ $\mathrm{cm}^{2} \mathrm{~s}^{-1}$ and $E_{1 / 2}^{\mathrm{r}}=-637.5 \mathrm{mV}$ vs. SCE. These data are in agreement with the half-wave potential and the limiting current obtained from the dc polarogram. It was found that the experimental $\sigma$-values do not differ more than $1 \%$ from the calculated values.

The quadrature component of the interfacial admittance, $Y^{\prime \prime}$, is more sensitive to small values of $p^{\prime}$. This can be utilized to calculate $p^{\prime}$ either by com- 


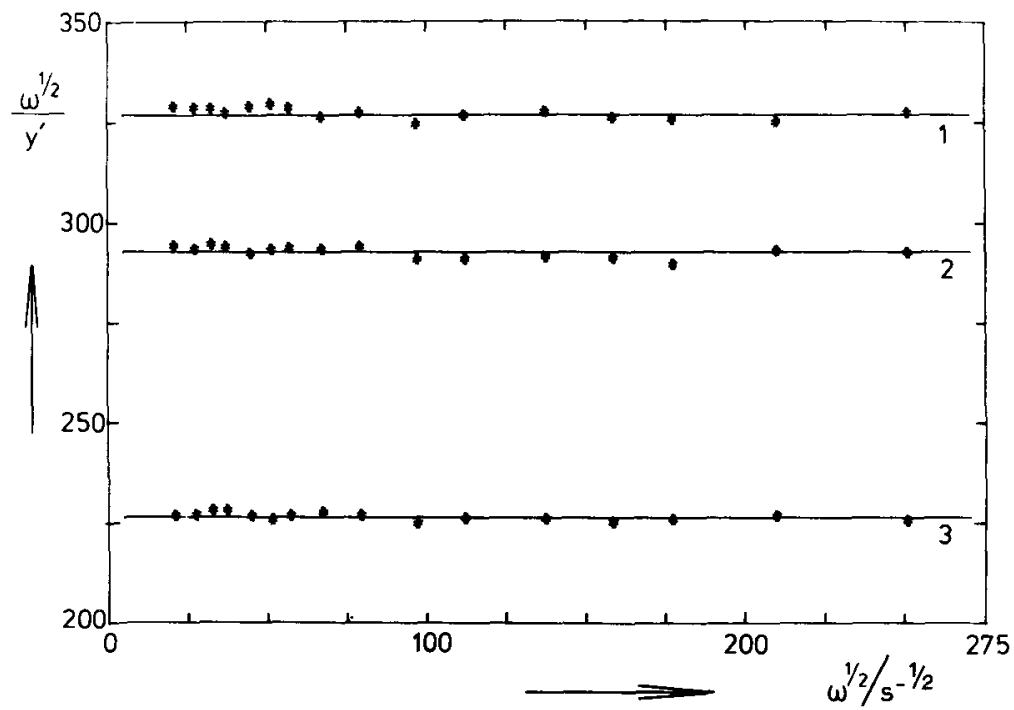

Fig. 6. Plot $\sqrt{ } \omega / Y^{\prime}$ vs. $\sqrt{ } \omega$ at three potentisl: (1) $E=-0.648 \mathrm{~V}$ vs. $\operatorname{SCE}$; (2) $E=-0.658 \mathrm{~V}$ vs. SCE; (3) $E=-0.623$ V vs. SCE.

bining eqns. (3) and (3a):

$Y^{\prime} /\left(Y^{\prime \prime}-\omega C_{\mathrm{d}}\right)=1+p=\cot \phi$

or by analyzing eqn. (3) in the form:

$\omega^{1 / 2} /\left(Y^{\prime \prime}-\omega C_{\mathrm{d}}\right)=2 \sigma\left(1+p+p^{2} / 2\right)$

In eqn. (8) $\phi$ is the phase angle of the faradaic impedance [28]. To perform this

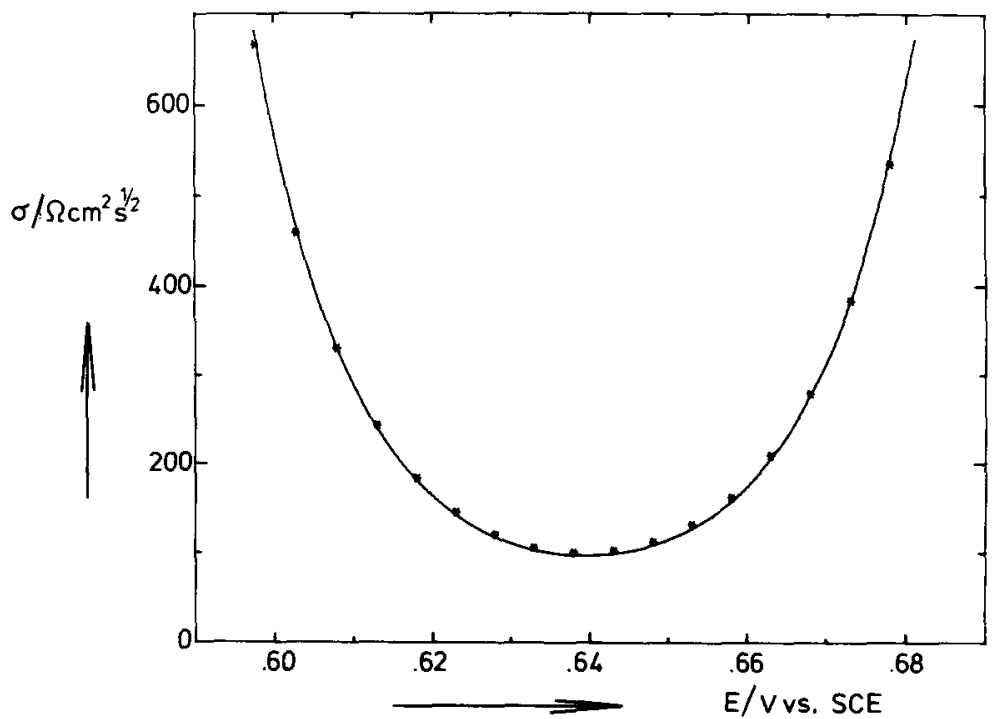

Fig. 7. Plot of $\sigma$ vs. potential. 


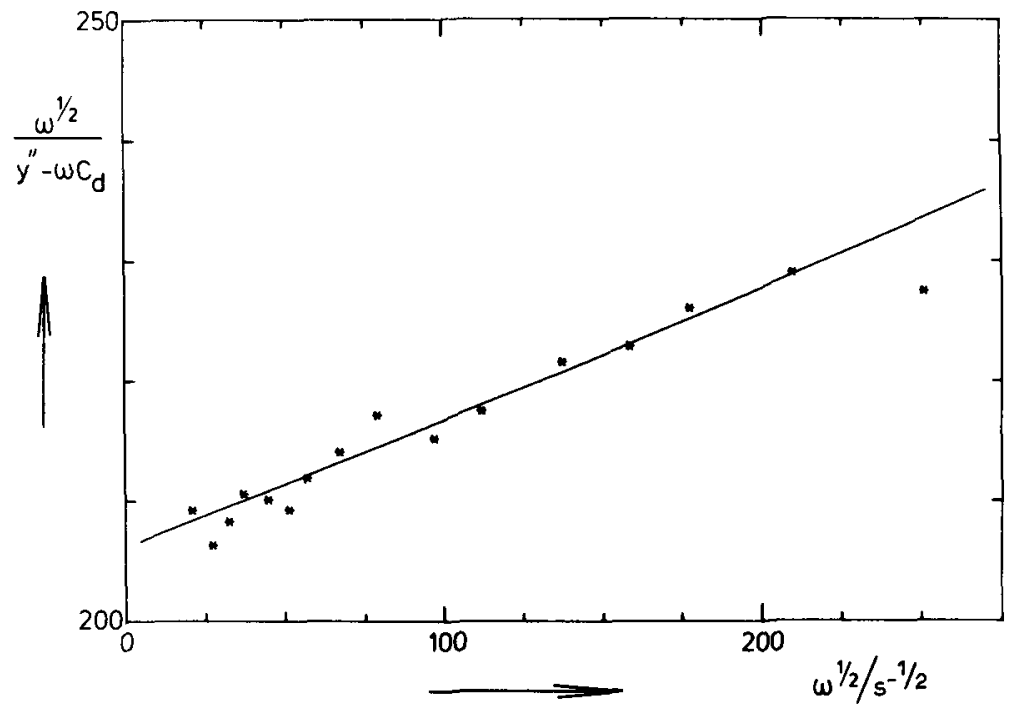

Fig. 8. Plot of $\sqrt{ } \omega /\left(Y^{\prime \prime}--\omega C_{\mathrm{d}}\right)$ vs. $\sqrt{ } \omega$ at $E=-0.628 \mathrm{~V}$ vs. SCE.

analysis we inserted $C_{\mathrm{d}}$-values obtained in the absence of the redox couple at $1 \mathrm{kHz}$. A typical plot of $\omega^{1 / 2} /\left(Y^{\prime \prime}-\omega C_{\mathrm{d}}\right)$ against $\omega^{1 / 2}$ is shown in Fig. 8 .

From the intercept and the slope it is found that $\sigma=125.5 \Omega \mathrm{cm}^{2} \mathrm{~s}^{-1 / 2}$ and $p^{\prime}=$ $0.5 \times 10^{-3} \mathrm{~s}^{1 / 2}$. From the analysis of $\omega^{1 / 2} / Y^{\prime}$ at the same potential $(-0.628 \mathrm{~V}$ vs. SCE) we find $\sigma=124$, while the application of eqn. (8) in the frequency range $70 \mathrm{~Hz}-10 \mathrm{kHz}$ yields $p^{\prime}=(0.7 \pm 0.1) \times 10^{-3} \mathrm{~s}^{1 / 2}$ as the mean value.

Similar calculations at the other potentials yield the $p^{\prime}$-values shown in Fig. 9.

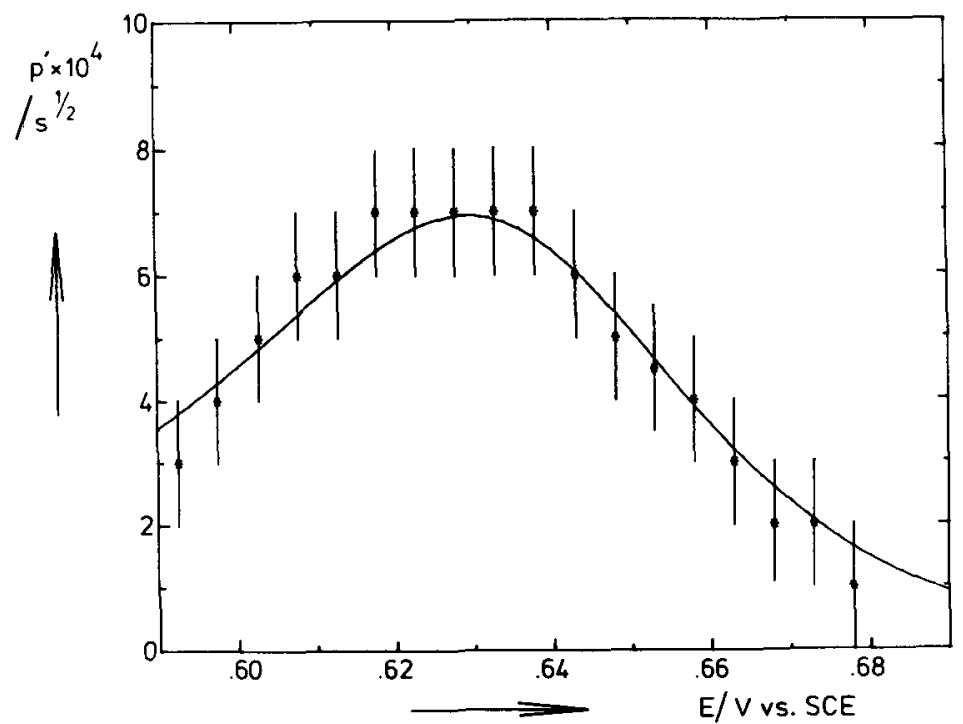

Fig. 9. Plot of $p^{\prime}$ vs. potential. Estimated errors of $1 \times 10^{-4} \mathrm{~s}^{1 / 2}$. Drawn curve: theoretical plot with $k_{\mathrm{s}}=3.2 \mathrm{~cm} \mathrm{~s}^{-1}$ and $\alpha=0.65$. 
The results obtained are consistent with the simple relationship $k_{\mathrm{f}}=k_{\mathrm{sh}}$ $\exp \left[-(\alpha n F / R T)\left(E-E^{0}\right)\right], k_{\mathrm{sh}}$ being the standard heterogeneous rate constant and $\alpha$ the cathodic transfer coefficient; in view of the accuracy we find $k_{\mathrm{sh}}=3$ to $4 \mathrm{~cm} \mathrm{~s}^{-1}$ and $\alpha=0.65 \pm 0.05$. This result is in good agreement with data reported by De Leeuwe [26] and Van der Pol [27], both obtained with the faradaic rectification technique. It is also evident that our set-up is superior to the former ac bridge, with which we were unable to detect the irreversibility quotient of the $\mathrm{Cd}^{2+}-\mathrm{KCl}$ system [3].

\section{(III.4) The influence of the detector delay}

As mentioned in Section (II.2) the filters in the network analyzer give rise to a slow response to the time-dependent signal to be measured at the DME. Since the time constant is known it is possible to estimate the effect of this drawback on the eventually determined parameters, using the simulation procedure published earlier [22]. To this end the following procedure was developed.

(1) Consider the measured $R_{\mathrm{s}}$ and $C_{\mathrm{s}}$ values for the time being as the real values at the time of measurement $t_{\mathrm{m}}$. The resistive component will be built up from three terms, viz.:

$R_{\mathrm{s}}=R_{\text {cap }}+\left(R_{\Omega}-R_{\text {cap }}\right)+\left(R_{\mathrm{s}}-R_{\Omega}\right)$

where $R_{\text {cap }}$ is the constant resistance of the capillary, $R_{\Omega}-R_{\text {cap }}$ the solution resistance which is proportional to $t_{\mathrm{m}}^{-1 / 3}$ and $\left(R_{\mathrm{s}}-R_{\Omega}\right)$ the interfacial resistance which is proportional to the reciprocal surface area, i.e. to $t_{\mathrm{m}}^{-2 / 3}$. Similarly $C_{\mathrm{s}}$, as a pure interfacial quantity, will be proportional to $t_{\mathrm{m}}^{2 / 3}$.

(2) During the time the drop is growing, the cell impedance will decrease according to:

$$
\begin{aligned}
& R_{\mathrm{s}}(t)=R_{\text {cap }}+\left(R_{\Omega}-R_{\text {cap }}\right)\left(t_{\mathrm{m}} / t\right)^{1 / 3}+\left(R_{\mathrm{s}}-R_{\Omega}\right)\left(t_{\mathrm{m}} / t\right)^{2 / 3} \\
& C_{\mathrm{s}}(t)=C_{\mathrm{s}}\left(t / t_{\mathrm{m}}\right)^{2 / 3}
\end{aligned}
$$

From these relations the admittance amplitude and phase angle are calculated and submitted to the digital simulation program. The program calculates the $R_{\mathrm{s}}$ and $C_{\mathrm{s}}$-values which would be measured, if these were the "real" values. For example, for the supporting electrolyte it is found that a "real" combination $R_{\mathrm{s}}\left(t_{\mathrm{m}}\right)=56.7 \Omega$ and $C_{\mathrm{s}}\left(t_{\mathrm{m}}\right)=1.41 \mu \mathrm{F}$ at $10 \mathrm{kHz}$ would lead to "observed" values $R_{\mathrm{s}}=56.85 \Omega$ and $C_{\mathrm{s}}=1.39 \mu \mathrm{F}$ at $t=t_{\mathrm{m}}$. The differences are considered as corrections, so that a "measured" combination $R_{\mathrm{s}}=56.7 \Omega$ and $C_{\mathrm{s}}=1.41 \mu \mathrm{F}$ is converted to $R_{\mathrm{s}}=56.55 \Omega$ and $C_{\mathrm{s}}=1.43 \mu \mathrm{F}$ as the "time" impedance components.

In Table 3 the data set, which led to Fig. 8, is treated in this way. The following conclusions can be drawn:

(1) Both the corrected $Y^{\prime}$-value and $Y^{\prime \prime}$-values differ systematically from the non-corrected values by $+1.5 \%$.

(2) The resulting $p^{\prime}$-values from the uncorrected series and the corrected series are almost equal.

(3) The resulting $\sigma$-value will naturally be $1.5 \%$ lower than was calculated from the uncorrected data. 
TABLE 3

Results obtained from measurements with a DME in a solution of $0.56 \mathrm{~m} M \mathrm{CdSO}_{4} 8 / 3 \mathrm{aq}$. in $1 M \mathrm{KCl}$ at $E=-0.628 \mathrm{~V}$ vs. SCE ${ }^{a}$

\begin{tabular}{|c|c|c|c|c|c|}
\hline Freq./Hz & $\left(R_{\mathrm{s}}-R_{\Omega}\right) / \Omega$ & $C_{\mathrm{s}} / \mu \mathrm{F}$ & $\begin{array}{l}Y^{\prime} \omega^{-1 / 2} \\
\times 10^{3}\end{array}$ & $\begin{array}{l}\left(Y^{\prime \prime}-\omega C_{\mathrm{d}}\right)- \\
\omega^{-1 / 2} \times 10^{3}\end{array}$ & $p^{\prime} \times 10^{3}$ \\
\hline \multirow[t]{2}{*}{70} & 152.9 & 13.1 & 4.080 & 4.015 & 0.77 \\
\hline & 150.65 & 13.3 & 4.142 & 4.075 & 0.79 \\
\hline \multirow[t]{2}{*}{120} & 111.5 & 10.1 & 4.096 & 4.019 & 0.71 \\
\hline & 109.85 & 10.25 & 4.157 & 4.078 & 0.71 \\
\hline \multirow[t]{2}{*}{170} & 90.9 & 8.51 & 4.089 & 3.988 & 0.77 \\
\hline & 89.55 & 8.64 & 4.148 & 4.048 & 0.76 \\
\hline \multirow[t]{2}{*}{220} & 77.6 & 7.52 & 4.090 & 3.979 & 0.75 \\
\hline & 76.45 & 7.63 & 4.150 & 4.078 & 0.75 \\
\hline \multirow[t]{2}{*}{320} & 61.4 & 6.30 & 4.098 & 3.953 & 0.83 \\
\hline & 60.5 & 6.40 & 4.164 & 4.013 & 0.85 \\
\hline \multirow[t]{2}{*}{420} & 51.4 & 5.54 & 4.091 & 3.936 & 0.77 \\
\hline & 50.65 & 5.62 & 4.151 & 3.993 & 0.77 \\
\hline \multirow[t]{2}{*}{520} & 44.5 & 5.03 & 4.101 & 3.930 & 0.76 \\
\hline & 43.85 & 5.11 & 4.169 & 3.988 & 0.79 \\
\hline \multirow[t]{2}{*}{720} & 35.5 & 4.36 & 4.125 & 3.916 & 0.79 \\
\hline & 34.95 & 4.42 & 4.179 & 3.974 & 0.77 \\
\hline \multirow[t]{2}{*}{1,000} & 27.8 & 3.77 & 4.110 & 3.913 & 0.63 \\
\hline & 27.4 & 3.83 & 4.170 & 3.968 & 0.64 \\
\hline \multirow[t]{2}{*}{1,500} & 20.6 & 3.18 & 4.132 & 3.841 & 0.78 \\
\hline & 20.3 & 3.23 & 4.198 & 3.899 & 0.79 \\
\hline \multirow[t]{2}{*}{2,000} & 16.2 & 2.84 & 4.130 & 3.852 & 0.65 \\
\hline & 15.95 & 2.88 & 4.185 & 3.907 & 0.64 \\
\hline \multirow[t]{2}{*}{3,000} & 11.4 & 2.44 & 4.125 & 3.835 & 0.55 \\
\hline & 11.25 & 2.48 & 4.200 & 3.891 & 0.58 \\
\hline \multirow[t]{2}{*}{4,000} & 8.9 & 2.20 & 4.122 & 3.739 & 0.65 \\
\hline & 8.75 & 2.22 & 4.154 & 3.781 & 0.62 \\
\hline \multirow[t]{2}{*}{5,000} & 7.2 & 2.04 & 4.135 & 3.734 & 0.61 \\
\hline & 7.1 & 2.07 & 4.181 & 3.769 & 0.62 \\
\hline \multirow[t]{2}{*}{7,000} & 5.2 & 1.84 & 4.149 & 3.675 & 0.62 \\
\hline & 5.15 & 1.87 & 4.216 & 3.700 & 0.67 \\
\hline \multirow[t]{2}{*}{10,000} & 3.6 & 1.68 & 4.174 & 3.640 & 0.58 \\
\hline & 3.55 & 1.70 & 4.230 & 3.678 & 0.60 \\
\hline
\end{tabular}

a The upper numbers at each frequency pertain to the uncorrected values $R_{\Omega}=56.7 \Omega$ and $C_{\mathrm{d}}=0.981 \mu \mathrm{F}$, the lower numbers contain the corrected values $R_{\Omega}=56.55 \Omega$ and $C_{\mathrm{d}}=$ $0.996 \mu \mathrm{F}$.

\section{CONCLUSIONS}

Network analysis by measurement of the transfer function is a rather common procedure nowadays, and with a view to all the dedicated instruments available its application to impedance or admittance measurement of electrochemical systems is obvious. Electrochemical systems, however, often have the property of being strongly non-linear and most commercially available instruments do not fully discriminate against overtones.

In the case of the measurement of the transfer function of an object that varies in time, like the DME, or in the case of a swept dc bias the slow response 


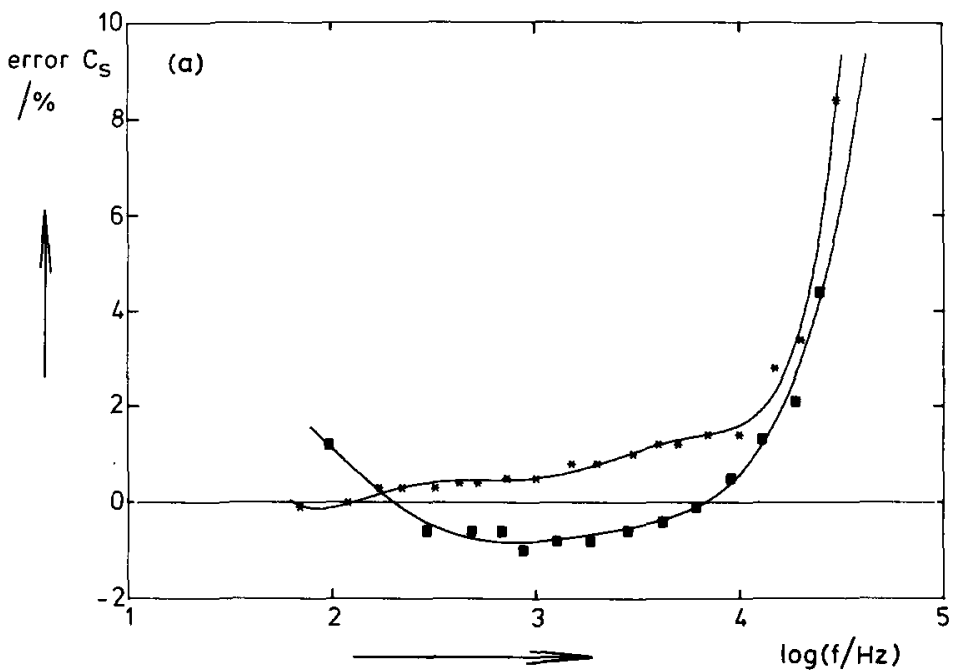

Fig. 10a. Plot of errors in $C_{\mathrm{s}}$ vs. $\log f$. (*) data from Table 1, (a) from ref. 18.

of the instrument must be taken into account.

At present, we believe, there are two approaches to transfer function measurement that seem both attractive and useful, i.e. the FFT approach advocated by Smith et al. [18] and the analog procedure inter alia described in this paper.

A fair though not ideal comparison between the two instruments can be made, we believe, by comparison of our Table 1 and the third data set in Table 1 of ref. 18. The latter data set we transferred into $R_{\mathrm{s}}$ and $C_{\mathrm{s}}$-values and we calculated the relative error $(\%)$ by comparison with the theoretical value. The results are given in Fig. 10, together with the data obtained with our instrument. It should be noted that this comparison is not completely justified

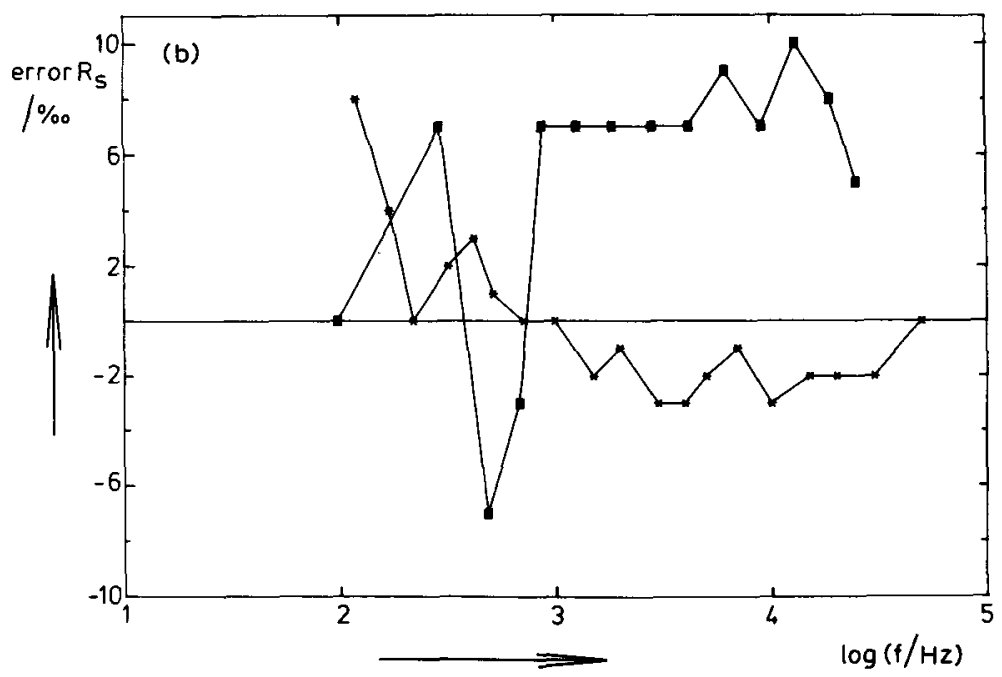

Fig. 10b. Plot of errors in $R_{\mathrm{s}}$, vs. $\log f$. Sources as in Fig. 10a. 
because the values of $R_{\mathrm{s}}$ and $C_{\mathrm{s}}$ obtained from ref. 18 are frequency dependent while ours are not. Nevertheless it gives an idea of the relative performances of the two instruments.

It can be seen that both instruments at high frequencies show an error in $C_{\mathrm{s}}$. In ref. 18 this phenomenon is ascribed to the perturbation being a stepped function. We think that it should also be realized that an increasing capacitive behavior of the network under test puts higher demands on the current follower that at higher frequencies might cause the results to deteriorate.

In our opinion the quality of the instrument should not be demonstrated by more or less closely mimicking the object. By doing so the technique becomes more equal to a substitution method that, of course, would always lead to a good result whatever the error in the instrument.

As yet a complete comparison of the methods does not seem possible, and therefore at present the preference for one or the other philosophy might depend largely on the knowledge and experience available, as well as on financial capacity. In any case, with the present state of electronics the advantages of the automatic measurement of cell admittances over bridge methods are clearly now well established, both as for ease of operation, efficiency in time consumption and, most important, accuracy in a large frequency range.

\section{ACKNOWLEGEMENT}

One of us (C.B.) acknowledges a travel grant of the Netherlands Organization for the Advancement of Pure Research (Z.W.O.) that enabled him to visit Professor D.E. Smith at the Northwestern University, Evanston, Ill., U.S.A.

\section{REFERENCES}

1 D.C. Grahame, J. Am. Chem. Soc., 71 (1949) 2975.

2 R. Parsons, Trans. Faraday Soc., 56 (1960) 1340.

3 M. Sluyters-Rehbach and J.H. Sluyters, Rec. Trav. Chim., 82 (1963) 535.

4 H. Gerischer, Z. Elektrochem., 58 (1954) 9.

5 J.H. Sluyters and J.C.C. Oomen, Rec. Trav. Chim., 79 (1960) 1011.

6 J. Schön, W. Mehl and H. Gerischer, Z. Elektrochem., 59 (1955) 144.

7 M.W. Breiter, J. Electroanal. Chem., 7 (1964) 38.

8 S. Shibata, Bull. Chem. Soc. Japan, 39 (1966) 779.

9 T. Takahashi and E. Niki, Talanta, 1 (1958) 245.

10 R. de Levie and A.A. Husovsky, J. Electroanal. Chem., 20 (1969) 181.

11 I. Epelboin and M. Keddam, J. Electrochem. Soc., 117 (1970) 1052.

12 B.J. Huebert, Thesis, Evanston, Illinois, 1971.

13 S.C. Creason and D.E. Smith, J. Electroanal. Chem., 36 (1972) 91.

14 S.C. Creason and D.E. Smith, J. Electroanal. Chem., 47 (1973) 9.

15 S.C. Creason and D.E. Smith, Anal. Chem., 45 (1973) 2401.

16 R.J. Schwall, A.M. Bond and D.E. Smith, Anal. Chem., 49 (1977) 1805.

17 R.J. Schwall, Thesis, Evanston, Illinois (1977).

18 R.J. Schwall, A.M. Bond, R.J. Loyd, J.G. Larsen and D.E. Smith, Anal. Chem., 49 (1977) 1797.

19 R.D. Armstrong, M.E. Bell and A.A. Metcalffe, J. Electroanal. Chem., 77 (1977) 287.

20 E.R. Brown, D.E. Smith and G.L. Booman, Anal. Chem., 40 (1968) 1411.

21 Ch. Yarnitzky, C.A. Wijnhorst, B. v.d. Laar, H. Reyn and J.H. Sluyters, J. Electroanal. Chem., 77 (1977) 39.

22 J.S.M.C. Breukel, M. Sluyters-Rehbach and J.H. Sluyters, J. Electroanal. Chem., 102 (1979) 303.

23 C.P.M. Bongenaar, M. Sluyters-Rehbach and J.H. Sluyters, to be published.

24 J.E.B. Randles, Trans. Symp. Electrode Proc., Philadelphia 1959, Wiley, New York, 1961, pp. 209, 325. 
25 H.H. Bauer, D.L. Smith and P.J. Elving, J. Am. Chem. Soc., 82 (1960) 2094.

26 R. de Leeuwe, M. Sluyters-Rehbach and J.H. Sluyters, Electrochim. Acta, 14 (1969) 1183.

27 F. van der Pol, M. Sluyters-Rehbach and J.H. Sluyters, J. Electroanal. Chem., 45 (1973) 377.

28 M. Sluyters-Rehbach and J.H. Sluyters in A.J. Bard (Ed.), Electroanalytical Chemistry, Vol. 4, Marcel Dekker, New York, 1970.

29 J.R. Delmastro and D.E. Smith, Anal. Chem., 38 (1966) 169. 